\title{
Fortegnelse over forfatternes adresser
}

Sognepræst Henrik True

Berghofstr. 10

D-24955 Harrislee.

Reader S.A.J. Bradley

University of York

Department of English Literature

Heslington, York

GB-YO1 5DD.

The Revd. Alan Gaunt

4 Greensgates Crescent

Little Neston, South Wirral

GB- CH64 OXH.

Canon, professor, dr. A.M. Allchin

1 Trem Yr Wyddfa

Bangor

Gwynedd, LL57 2ER

North Wales

United Kingdom.

Rektor Niels Thomsen

Østerende 8

Ballum

6261 Bredebro.

Professor, dr.theol. Jakob Balling

Voldbækvej 3

8220 Brabrand.

Museumsdirektør, mag.art. Nina Hobolth

Nordjyllands Kunstmuseum

Kong Christians Allé 50

9000 Aalborg. 
Museumsinspektør, ph.d. Peter Nørgaard Larsen Statens Museum for Kunst

Sølvgade 48-50

1307 København K.

Professor dr.theol. K.E.Bugge

Dronningeengen 22

2950 Vedbæk

Stipendiat, ph.d. Johannes Adamsen

Institut for Systematisk Teologi

Det Teologiske Fakultet

Aarhus Universitet

Tåsingegade 3

8000 Århus C.

Sognepræst, dr.theol. Bent Christensen

Karlslundevej 12

Døllefjelde

4990 Sakskøbing.

Universitetslektor, mag.art. Jens Peter Ægidius

Kastanievej 24

5672 Broby.

Lektor Aage Jørgensen

Bakkelodden 2

8320 Mårslet

Ph.d.-stipendiat Erik Kelstrup

St. Blichers Vej 17

8230 Aabyhøj

Programmedarbejder, cand.pæd. Thorstein Balle

Kastanievej 13

1876 Frederiksberg C. 
Rektor E. Harbsmeier

Psætehøjskolen

Kirkeallé 2

6240 Løgumkloster.

Højskoleforstander Jørgen Carlsen

Testrup Højskole

Testrupvej 100

8320 Mårslet.

Forskningslektor, lic.theol.Kim Arne Pedersen

Grundtvig Centeret

Det Teologiske Fakultet

Aarhus Universitet

Tåsingegade 3

8000 Århus C.

Provst, lic.theol. Peter Balslev-Clausen

Ahlmanns allé 14

2900 Hellerup. 